\title{
Jurist-Diction
}

Volume 2 No. 6, November 2019

Histori artikel: Submit 19 September 2019; Diterima 16 Oktober 2019; Diterbitkan online 1 November 2019.

\section{Klausula Counter-claim dalam Bilateral Investment Treaty Indonesia}

\author{
Nabilla Zelda Nasution \\ nabillazelda.nst@gmail.com \\ Universitas Airlangga
}

\begin{abstract}
The Investor-State Dispute Settlement (ISDS) is a dispute resolution mechanism between investors and host state due to a violation of International Investment Law. Based on UNCTAD data, the reasons often asked in the ISDS lawsuit generally include four issues, namely Most Favored Nations, National Treatment, Non-Exproriation, and Fair and Equitable Treatment. However, the regulation of investment dispute settlement with the ISDS mechanism is considered to be more favorable to investors than to the host state because most of the IIA allows ISDS to be submitted by investors, and in practice investors are the only plaintiffs allowed. The imbalance of the position of the parties in the ISDS mechanism gives the thought of counter-claims as an effort to balance the position of investors and the host state in the ISDS mechanism. Besides the importance of counter-claiim in the ISDS mechanism, among others, because there is no uniform rule regarding counter-claims, counter-claims allow respondents to seek justice in the same forum so that it is more efficient. As well as for host states, counter-claims can be used to clean the host state's reputation for a lawsuit filed by an investor. This study examines counterclaim clauses that can be adopted in Indonesian BIT so that they can balance the position of the parties in the ISDS mechanism, especially Indonesia as a host state. Legal research used is the conceptual approach, statute approach, and case approach in discussing counterclaim in the ISDS mechanism and in analyzing the formulation of counterclaim clauses that can be adopted in the Bilateral Investment Treaty (BIT) Indonesia.
\end{abstract}

Keywords: Bilateral Investment Treaty (BIT); Counter-claim; Investor-State Dispute Settlement (ISDS).

\begin{abstract}
Abstrak
Investor-State Dispute Settlement (ISDS) merupakan suatu mekanisme penyelesaian sengketa antara investor dan negara penerima investasi (host state) karena suatu pelanggaran terhadap Hukum Investasi Internasional. Berdasarkan data UNCTAD, alasan yang sering diajukan dalam gugatan ISDS umumnya meliputi empat hal permasalahan yakni Most Favoured Nations, National Treatment, Non Exproriation, dan Fair and Equitable Treatment. Namun pengaturan penyelesaian sengketa investasi dengan mekanisme ISDS dianggap lebih berpihak kepada pihak investor dibandingkan kepada host state karena sebagian besar IIA mengijinkan ISDS diajukan oleh investor, dan dalam prakteknya investor merupakan satu-satunya penggugat yang diizinkan. Ketidakseimbangan kedudukan para pihak dalam mekanisme ISDS memberikan pemikiran counter-claim sebagai upaya menyeimbangkan kedudukan investor dan host state dalam mekanisme ISDS. Selain itu pentingnya counter-claiim dalam mekanisme ISDS antara lain karena belum ada aturan yang seragam mengenai counter-claim, counter-claim memungkinkan responden untuk mencari keadilan di forum yang sama sehingga lebih efisien. Serta bagi host state, counter-claim dapat digunakan untuk membersihkan reputasi host state atas gugatan yang diajukan oleh investor. Penelitian ini mengkaji klausula counterclaim yang dapat diadopsi dalam BIT Indonesia sehingga dapat menyeimbangkan kedudukan para pihak dalam mekanisme ISDS, khususnya Indonesia sebagai host state. Penelitian hukum yang digunakan adalah pendekatan konseptual (conseptual approach), pendekatan perundang-udangan (statute approach), dan pendekatan kasus (case approach) dalam membahas counterclaim dalam mekanisme ISDS serta dalam menganalisa rumusan klausula counterclaim yang dapat di adopsi dalam Bilateral Investment Treaty (BIT) Indonesia.
\end{abstract}

Kata Kunci: Bilateral Investment Treaty (BIT); Counter-claim; Investor-State Dispute Settlement (ISDS). 


\section{Pendahuluan}

Mekanisme penyelesaian sengketa Investasi antara Investor dan negara (ISDS) pertama kali dikenal melalui instrumen perjanjian bilateral antar negara yang biasa disebut dengan Bilateral Investment Treaty (BIT). ${ }^{1}$ Sebelum BIT dikenal, sengketa Investasi melibatkan negara melawan negara lain, sehingga Investor tidak dapat menuntut negara secara langsung. ${ }^{2}$ Oleh karena itu apabila negara melakukan pelanggaran, Investor harus meminta negaranya untuk mengajukan gugatan atas nama Investor kepada International Court of Justice (ICJ). ${ }^{3}$ Akan tetapi dengan adanya mekanisme ISDS dalam BIT, maka investor dapat mengajukan tuntutan terhadap host state tanpa melalui proses penyelesaian sengketa domestik home state. ${ }^{4}$

Bilateral Invetment Treaty (BIT) adalah sebuah perjanjian antara dua negara berdaulat yang dilakukan oleh investor suatu negara (home state) di wilayah negara lain (host state). ${ }^{5}$ BIT mengatur mengenai standar-standar perlindungan investasi yang harus dilakukan oleh host state, seperti: ${ }^{6}$

a. perlakuan yang setara dan adil atau tidak ada diskriminasi dari segala jenis investasi baik asing maupun domestik;

b. perlindungan dan keamanan penuh yang memuat kewajiban Negara untuk memberikan ganti rugi atas kerugian yang diderita oleh korporasi akibat perang, konflik bersenjata, revolusi, keadaan darurat Negara, kerusuhan, ataupun pemberontakan. Biasanya perlindungan ini dalam bentuk pemberian kompensasi atau pemulihan;

c. perlindungan dari tindakan pengambil-alihan atau nasionalisasi dan mengharuskan pemberian kompensasi ganti rugi atas tindakan tersebut;

d. mekanisme penyelesaian sengketa, yang mensejajarkan antara level investor dengan negara atau dikenal dengan "Investor-State Dispute Settlement" (ISDS).

\footnotetext{
${ }^{1}$ Andi Muhammad Faiz. 'Penyelesaian Sengketa Investor-State Dispute Settlement (ISDS) Melalui International Centre for Settlement of Investment Dispute (ICSID) Ditinjau Dari Perspektif Ham Internasional', (2017) Universitas Hasanuddin.[17].

${ }^{2}$ ibid.

${ }^{3}$ S. D. Franck, 'Foreign Direct Investment: Investment Treaty Arbitration and the Rule of Law’, (2007), Global Business \& Development Law Journal.[337].

4 The Directorate General for Trade of the Europian Commission, 'Factsheet on Investor-State Dispute Settlement : Europian Union'. (Europian Comission. 2015) <http://trade.ec.europa.eu/doclib/docs/2015/january/tradoc_153046.pdf> accessed 04 Maret 2019.

${ }^{5}$ Marc Jacob, 'Investment Bilateral Treaties' (2013) Max Planck Encyclopedia of Public International Law (MPEPIL). [3].

${ }^{6}$ Rachmi Hertanti dan Rika Febriani, 'Bilateral Investment Treaty (BITs) "Negara VS Korporasi” Seri Buku Panduan Memahami: Perjanjian Investasi Internasional dan Gugatan Terhadap Indonesia', (Indonesia for Global Justice 2014). [4].
} 
Menurut United Nation Conference on Trade and Development (UNCTAD), hingga akhir Juli 2018 jumlah kasus ISDS yang berbasis BIT telah mencapai 904 kasus $^{7}$ yang didominasi oleh sektor power generation dan suplai tenaga listrik; minyak dan gas maupun pertambangan. ${ }^{8}$ Berdasarkan data UNCTAD, alasan yang sering diajukan dalam gugatan ISDS umumnya meliputi empat hal permasalahan yakni:

\section{Most Favoured Nation (MFN)}

Most Favoured Nation (MFN) is treatment accorded by the granting State to the beneficiary State, or to persoons or things in a determined relationship with that State, not less favourable than treatment extended by the granting State to a third State or to persons or things in the same relationship with that third State. ${ }^{9}$ MFN merupakan prinsip atas kepastian atau persamaan kondisi yang kompetitif antara investor yang berasal dari negara yang berbeda. Contoh gugatan yang diajukan ke ISDS bedasarkan prinsip MFN adalah Telenor Mobile Communication A.S v The Republic of Hungary, ICSID Case No ARB/04/15. Putusan 13 September 2006.

\section{Fair and Equitable Treatment (FET)}

FET merupakan standar perlindungan mutlak yang berlaku untuk investasi dalam memberikan kedudukan tanpa mengacu pada bagaimana investasi atau entitas lain diperlakukan oleh host state. ${ }^{10}$ Secara umum, banyak International Investment Agreement (yang selanjutnya disebut IIA), termasuk BIT Indonesia yang tidak memberikan definisi tentang standar FET, bahkan jika BIT memberikan definisi, definisi tersebut tidak spesifik. Kondisi ini cenderung ditafsirkan secara luas sebelum adanya forum ISDS, sehingga hampir semua tindakan negara yang merugikan investor dapat dianggap sebagai pelanggaran standar ini. Comtoh gugatan yang diajukan bedasarkan prinsip FET ini adalah dalam kasus Rafat Ali

\footnotetext{
${ }^{7}$ UNCTAD, 'Review of ISDS Decissions in 2018', (2018) <https://investmentpolicyhub. unctad.org/News/Database/Home/1604> accessed 4 Maret 2019.

8 ibid.

${ }^{9}$ United Nations, 'Yearbook of the International Law Comission 1978', (1979), Volume II Part Two, United Nations. [27].

${ }^{10}$ United Nations Conference on Trade and Development, 'UNCTAD Series on Issues in International Investment Agreement II: Fair and Equitable Treatment', (United Nations 2012).
} 
tahun 2011, Indonesia dituntut karena melanggar Pasal 2 ayat (1) dan Pasal 4 Perjanjian Investasi Bilateral (BIT) Indonesia-Inggris tentang FET. Penambangan Churchill juga menggunakan pelanggaran FET dalam gugatannya terhadap Indonesia pada tahun 2015.

\section{National Treatment (NT)}

NT didefinisikan sebagai prinsip perlakuan negara yang sama terhadap investor asing dengan investor domestik dalam negeri pada keadaan yang sama. Sehingga standar NT memastikan tingkat kesetaraan kompetitif antara investor asing dengan investor domestik. ${ }^{11}$

\section{Expropriation}

Expropriation umumnya berhubungan dengan pengambilalihan properti atau perusahaan tertentu dimana hak kepemilikan berada pada pihak pemerintah atau dialihkan oleh pemerintah pada pengusaha lain. ${ }^{12}$ Banyaknya klaim yang ditujukan kepada host state, membuat host state mengalami banyak kerugian, baik karena harus memberikan ganti rugi bedasarkan putusan pengadilan maupun karena banyaknya biaya yang harus dikeluarkan dalam proses penyelesaian sengketa. ${ }^{13}$

Pengaturan penyelesaian sengketa investasi dengan mekanisme ISDS dapat menjadi kekhawatiran bagi banyak pihak karena mekanisme tersebut dianggap lebih berpihak kepada pihak investor dibandingkan kepada negara. ${ }^{14}$ Sebagian besar IIA mengijinkan ISDS diajukan oleh investor, dan dalam prakteknya investor merupakan satu-satunya penggugat yang diizinkan. ${ }^{15}$ IIA mengizinkan investor untuk mengajukan gugatan ke ISDS atas namanya sendiri atau atas nama perusahannya. ${ }^{16}$

\footnotetext{
${ }^{11}$ United Nations Conference on Trade and Development, 'UNCTAD Series on Issues in International Investment Agreement II :National Treatment', (United Nations 1999). [1].

${ }^{12}$ United Nations Conference on Trade and Development, 'UNCTAD Series on Issues in International Investment Agreement II: Exppropriation', (United Nations 2012). [5].

${ }^{13}$ International Institute for Sustainable Development (IISD), 'Investment Treaties \& Why They Matter to Sustainable Development: Question \&Answers', (2012). [7].

${ }^{14}$ Indonesia for Global Justice. 'Lembar Fakta Ancaman Perjanjian TPP : Masyarakat Indonesia \#TolakTPP', (2016). [1].

${ }^{15} \mathrm{UNCTAD}$, 'UNCTAD Series on Issues in International Investment Agreements II :Scope and Definition', ( New York 2015). [180].

16 ibid.
} 
Oleh karena ketidakseimbangan kedudukan para pihak dalam mekanisme ISDS maka munculah ide counter-claim sebagai upaya menyeimbangkan kedudukan investor dan host state dalam mekanisme ISDS. Counter-claim merupakan gugatan balik dari tergugat kepada penggugat.

Ketidakseimbangan kedudukan para pihak dalam mengajukan klaim pada mekanisme ISDS tersebut memunculkan pentingnya counter-claim karena: ${ }^{17}$

1. Belum ada aturan yang seragam mengenai counter-claim karena counter-claim merupakan hal yang baru.

2. Counter-claim sangat jarang terjadi, dari $684^{18}$ BITs yang digugat di ISDS, gugatan counter-claim tidak melebihi $15^{19}$ kasus.

3. Counter-claim memungkinkan responden untuk mencari keadilan di forum yang sama sehingga lebih efisien.

4. Bagi host state, counter-claim dapat digunakan untuk membersihkan reputasi suatu negara atas gugatan yang diajukan oleh investor.

\section{Metode Penelitian}

Tipe penelitian hukum yang dgunakan dalam tulisan ini adalah penelitain yuridis normatif. Tipe penelitian yuridis normatif merupakan pendekatan masalah dengan cara meneliti asas-asas hukum dan sistematika hukum yang didasarkan pada peraturan perundang-undangan yang berlaku. ${ }^{20}$ Serta dilakukan penelitian kepustakaan dan penelitian kasus untuk menunjang materi dari hasil penelitian perundang-undangan.

\section{Counter-Claim dalam Investor-State Dispute Settlement}

Definisi Bilateral Investment Treaty menurut United Conference on Trade and Development (UNCTAD) dinyatakan:

Bilateral Investment Treaty are agreements between two countries for the

\footnotetext{
${ }^{17}$ Kamran Musayev, 'Counterclaims in treaty-based investment arbitration', (2017), University of Oslo Norwegia. [5].

${ }^{18}$ UNCTAD, 'Investor-State Dispute Settlement: Review Of Developments In 2017', (2018). [1].

${ }^{19}$ Atanasova, Benoit and Ostřanský, 'The Legal Framework for Counterclaims in Investment Treaty Arbitration', (2014), Journal of International Arbitration. [358].

${ }^{20}$ Soejono dan H. Abdurrahman, Metode Penelitian Hukum (Rineka Cipta 2003). [56].
} 
reciprocal encouragement, promotion, and protection of investments in each other's territories by companiees based in either country. Treaties typically cover the following areas : scope and definition of investment, admission and establishment, national treatment, most favoured nation treatment, fair, and equitable treatment, compensation, in the event of expropriation or damage to the investment guarantees of free transfers of funds, and dispute settlement mechanisms, both state-state and investor state. ${ }^{21}$

BIT ini mengatur mengenai standar-standar perlindungan investasi yang harus dilakukan oleh negara tuan rumah (host state), seperti: ${ }^{22}$

a. perlakuan yang setara dan adil atau tidak ada diskriminasi dari segala jenis investasi baik asing maupun domestik;

b. perlindungan dan keamanan penuh yang memuat kewajiban Negara untuk memberikan ganti rugi atas kerugian yang diderita oleh korporasi akibat perang, konflik bersenjata, revolusi, keadaan darurat Negara, kerusuhan, ataupun pemberontakan. Biasanya perlindungan ini dalam bentuk pemberian kompensasi atau pemulihan. dalam pasal 28 UNCITRAL Model Law menyatakan bahwa kegagalan setiap penunjukan oleh para pihak dalam sidang arbitrase akan diterapkan hukum para pihak yang berlaku. Dalam hipotesa ini klausula rebus sic stantibus hanya bisa diterapkan apabila bagian dari hukum nasional yang dipilih berdasarkan aturan hukum dari yang bersengketa. Tetapi hal ini tidak berarti kluasula tersebut dapat secara langsung diterapkan dalam hukum yang berlaku. ${ }^{23}$

c. perlindungan dari tindakan pengambil-alihan atau nasionalisasi dan mengharuskan pemberian kompensasi ganti rugi;

d. mekanisme penyelesaian sengketa, yang mensejajarkan antara level investor dengan negara atau dikenal dengan "Investor-State Dispute Settlement (ISDS)".

Bagi host state, BIT dapat menarik investasi asing dengan memberikan jaminan untuk melindungi investor dari Negara-negara pihak yang berinvestasi, dengan demikian host state berkomitmen untuk menyediakan iklim investasi yang menguntungkan yang mencakup perlakuan yang adil dan setara terhadap para pihak, memberikan hubungan timbal balik yang saling menguntungkan berdasarkan keyakinan bahwa menjadi pihak dalam BIT akan meningkatkan arus investasi asing, meningkatkan pembangunan, dan menghasilkan kemakmuran

${ }^{21}$ UNCTAD, 'The Investment Policy Framework', (UNCTAD 2017) <www.investmentpolicyunctad.org>, accessed 2 Februari 2019.

${ }^{22}$ Rachmi Hertanti dan Rika Febriani, Op Cit. [4].

${ }^{23}$ Gattopardo and Luchino Visconti, 'Rebus Sic Stantibus: A Comparative Analysis For International Arbitration', (Studio Legalle Asosciato 2012), <http://ssrn.com/abstract=2103641> Accessed 13 Juli 2019. 
ekonomi host state. ${ }^{24}$ Bagi investor, BIT dapat memberikan perlindungan dari tindakan legislatif, peraturan atau yudisial oleh host state jika tindakannya berupa: pengambilalihan, baik secara langsung maupun tidak langsung; ketidakadilan, termasuk tindakan yang melanggar ekspektasi investor; perlakuan diskriminatif baik dengan warganegara atau investor dari Negara lain; atau melanggar kewajiban investasi atau usaha dari host state. ${ }^{25}$

BIT sebagian besar dirancang untuk melindungi investor asing dan tidak mempertimbangkan kewajiban dan standar untuk melindungi faktor non-ekonomi host state seperti hak manusia, hak lingkungan, serta ketentuan sosial atau sumber daya alam dan ketika klausul tersebut disepakati, formulasi secara hukum menjadi sangat terbuka dan tidak dapat diprediksi. ${ }^{26}$ BIT dikritik karena secara terbuka memberikan kewajiban pada host state tetapi sangat jarang membebankan kewajiban pada Negara investor. ${ }^{27}$

Menurut seorang ahli hukum investasi internasional, Scott Miller ISDS merupakan: Investor state dispute settlement (ISDS), a provision in Bilateral Investment Treaties (BITs) and other internasional investment agreements that allows investors to enter arbitration with states over treaty breach, where those breaches created lost to the investor. ${ }^{28}$

Counter-claim sangat penting untuk diatur dalam perjanjian, karena: ${ }^{29}$

1. Masalah counter-claim dalam perjanjian arbitrase adalah hal baru sehingga belum ada aturan yang seragam. Kasus couter-claim pertama dalam perjanjian

${ }^{24}$ E Aisbett, 'Bilateral Investment Treaties And Foreign Direct Investment: Correlation Versus Causation’, (2007), 1032 Cudare Working Paper. [5].

${ }^{25}$ Gazzini, E. De Brabandere, ed., 'Bilateral Investment Treaties', (2012), Laussane International Law. [21].

${ }^{26}$ Wolfgang Alschner, 'Americanization of the BIT Universe: The Influence of Friendship, Commerce and Navigation (FCN) Treaties on Modern Investment Treaty Law', (2002), 5 Goettingen Journal of International Law. [475-476].

${ }^{27}$ Surya P. Subedi, 'The Challenge Of Reconciling The Competing Principles Within The Law Of Foreign Investment With Special Reference To The Recent Trend In The Interpretation Of The Term Expropriation', (London Pubisher 2006).[126].

${ }_{28}$ Miller, Scott, 'Investor-State Dispute Settlement : A Reality Check, Center for Strategic and International Studies', (London Publisher 2015). [V].

${ }^{29}$ Kamran Musayev, Op. Cit. [5-6]. 
arbitrase yakni kasus Genin v Estonia (putusan 2001). ${ }^{30}$ Namun dalam kontrak bedasarkan investasi arbitrase lebih dulu muncul kasus Andriano Gardella S.p.A v Republik Pantai Gading (Putusan 1977). ${ }^{31}$ Sebagian besar kasus perjanjian arbitrase dimana host state mengajukan counter-claim melawan investor telah diputuskan dalam lima tahun terakhir. ${ }^{32}$

2. Counter-claim dalam perjanjian arbitrase sangat jarang terjadi. Hingga kini terdapat $684 .{ }^{33}$ BITs yang digugat di investor-state dispute settlement. Namun jumlah negara yang mengajukan counter-claim terhadap investor tidak melebihi $15 .{ }^{34}$ Sejauh ini hanya satu kasus counter-claim yang berhasil. ${ }^{35}$

3. Counter-claimdapatmeningkatkan efisiensiperadilandengan"mengkoordinasikan penanganan beberapa klaim dalam satu waktu"36. Mempertimbangkan klaim utama dan counter-claim yang berkaitan sehingga menjamin hasil yang konsisten yang mana hal itu tidak terjamin bila diperiksa secara terpisah. ${ }^{37}$

Oleh karena itu counter-claim memungkinkan responden untuk mencari keadilan di forum yang sama agar tidak melanjutkan banding ke pengadilan. ${ }^{38}$ Counter-claim juga dapat digunakan untuk menghindari kerugian finansial yang ditimbulkan karena keterlambatan antara putusan klaim utama dengan putusan counter-claim..$^{39}$ Lebih lanjut lagi counter-claim dapat memberikan putusan yang lebih adil dengan memastikan bahwa fakta tambahan tidak dihilangkan. ${ }^{40}$

Counter-claim dalam perjanjian arbitase investasi dapat menjadi instrumen yang efisisen terhadap pelanggaran yang dilakukan investor. Ketakutan akan digugat oleh host state membuat investor bertindak sesuai dengan hukum host state. Oleh

${ }^{30}$ Dafina Atanasova, [et.,al.], 'Counter-claims in Investor-State Dispute Settlement (ISDS) under International Investment Agreements (IIAs)', (2012), Graduate Institute Centre For Trade And Economic Integration.[4].

${ }^{31}$ Mark Friedman dan Ina Popova, 'Can State Counter-claims Salvage Investment Arbitration?’, (2014), 8 World Arbitration \& Mediation Review.[145].

32 Kelsey Brooke Farmer, 'The Best Defence is a Good Offense - State Counter-claims in Investment Treaty Arbitration’, (2016), Victoria University. [4].

${ }^{33}$ UNCTAD, 'Investor-State Dispute Settlement: Review Of Developments In 2017', <http:// www.invetmentpoicy.unctad.org/isdsreview2017>, Accessed 9 April 2019.

${ }^{34}$ Atanasova, Benoit and Ostřanský, Op.Cit., [343].

${ }^{35}$ Burlington Resources Inc. v. Republic of Ecuador, ICSID Case No. ARB/08/5, Decision on Ecuador's Counter-claims, 7 February 2017. The Tribunal ordered Burlington to pay environmental damage in an amount of USD 39,199,373.

${ }^{36}$ Kamran Musayev, Op.Cit, [6].

${ }^{37}$ ibid.

${ }^{38}$ Guido Carducci, 'Dealing with Set-off and Counter-claims in International Commercial and Investment Arbitration', (2012), 4 Transnational Dispute Management. [2].

${ }^{39}$ Kamran Musayev,Op.Cit, [6].

${ }^{40}$ ibid. 
karena itu Investor dapat menolak untuk mengajukan klaim arbitrase jika mereka mengantisipasi adanya counter-claim. ${ }^{41}$

Bagi host state counter-claim juga dapat berfungsi sebagai alat guna menghapus reputasi host state yang rusak karena tuduhan tidak berdasar yang diajukan oleh investor. ${ }^{42}$

Praktek menunjukkan counter-claim dalam perjanjian arbitrase diizinkan secara prinsip. ${ }^{43}$ Namun hal tersebut tergantung pada faktor-faktor tertentu, yakni:

1. counter-claim harus berada di bawah persetujuan pihak yang bersengketa (host state dan investor) dan

2. counter-claim harus memiliki hubungan yang erat dengan klaim utama.

Sebagaimana dinyatakan di atas, dua syarat tersebut diperlukan untuk menerima counter-claim yang dikemukakan oleh suatu negara yaitu persetujuan dan hubungan antara klaim pokok dan counter-claim. Persetujuan merupakan unsur yang memberikan yurisdiksi kepada pengadilan. Jika yurisdiksi pengadilan bersandar pada persetujuan para pihak, maka persetujuan para pihak harus menjadi unsur penting untuk menyatakan yurisdiksi tersebut. ICJ menetapkan aturan dasar bahwa persetujuan menyatakan landasan yurisdiksinya. ${ }^{44}$

\section{Counter-claim dalam BIT Indonesia}

Berikut merupakan contoh klausula penyelesaian sengketa antara para pihak perjanjian dengan investor yang terdapat dalam beberapa BIT Indonesia.

\section{a. BIT antara Indonesia dan Bulgaria :}

Article 8

(2) If such a dispute cannot be settled within a period of six months from the date either party to the dispute requested amicable settlement the investor concerned may submit the dispute to:

a) the competent court of the Contracting Party concerned;

b) In case of disputes with regard to Articles IV, V and VI of this Agreement the investor concerned may, instead, choose to submit the dispute for

${ }^{41}$ ibid. [10].

42 ibid, [12].

${ }^{43}$ Kelsey Brooke Farmer, Op.Cit, [4].

${ }^{44}$ Michael Waibel, 'Corfu Channel Case in Max Planck Encyclopaedia of Public International Law', (Oxford University Press 2010). [2]. 
settlement by arbitration to:

-- an ad-hoc arbitral tribunal to be established under the Arbitration Rules of the United Nations Commission on International Trade Law (UNCITRAL) or,

-- the International Centre for Settlement of Investments Disputes (ICSID) set up by Convention of Investment Disputes between States and Nationals of other States done at Washington, March 18th 1965, in case both Contracting Parties become signatories of this Convention.

\section{b. BIT antara Indonesia dan Algeria :}

Article 8

(2) If such a dispute cannot be settled within a period of six months from the date of a written notitication by which either party requested amicable settlement, the dispute shall at the request of the investor concemed be submitted either to the judicial procedures provided by the Contracting Party concerned or to international arbitration or conciliation.

\section{c. BIT antara Indonesia dan Singapura :}

Article 8

(2) If the dispute cannot be settled within a period of six months from the date of the notice referred to in paragraph (1) then, unless the parties have otherwise agreed, it shall upon the written request of the investor concerned, be submitted either to:

a. The competent court of the Contracting Party concerned for a decision;

b. Any regional center for arbitration in ASEAN

Beberapa contoh BIT yang telah ditandatangani oleh Indonesia di atas menggambarkan keseluruhan BIT yang telah ditandatangani oleh Indonesia hingga saat ini. Pada pengaturan mengenai klausula penyelesaian sengketa, disebutkan bahwa hanya investor yang dapat membawa atau menginisiasi sebuah klaim ke ISDS. Maka, BIT Indonesia belum mengakomodasi ketentuan counter-claim sehingga Indonesia tidak dapat membawa klaim ke ISDS ketika investor melakukan pelanggaran kepada Indonesia sebagai host state.

Terdapat tiga opsi dalam membentuk rumusan counter-claim diantaranya yakni ${ }^{45}$ :

${ }^{45}$ Dafina Atanasova, Op.Cit, [56-60]. 


\section{a. Melalui klausula yurisdiksi}

Salah satu kendala host state dalam memasukkan counter-claim adalah karena sempitnya klausula yurisdiksi yang membatasi yurisdiksi pengadilan hanya untuk menyelesaikan masalah yang berkaitan dengan kewajiban host state. Terdapat dua opsi bila melalui klausula yurisdiksi, yakni:

1. Menggunakan klausula yurisdiksi yang luas

Any dispute concerning investments between one of the contracting parties and a national or company of the other contracting party is settled amicably between the two parties concerned. If such a dispute was not settled within a delay of six months starting from the moment when it was brought by one or the other party to the dispute, it is submitted by request of one or the other of the parties, (to arbitration). ${ }^{46}$

2. Memasukkan klausula counter-claim secara tegas

"The Respondent shall have the right to assert any and all counterclaims which arise out of the investment that constitutes the subject matter of the primary claim" 47

\section{b. Menambah kewajiban Investor}

Penambahan kewajiban investor yaitu dalam hal kepatuhan investor terhadap hukum negara penerima investasi akan memungkinkan majelis pengadilan dapat mendengarkan counter-claim bahkan ketika klausula yurisdiksinya bersifat sempit. Namun tetap counter-claim tersebut juga harus memenuhi unsur yang kedua yakni tentang hubungan counter-claim terhadap klaim utama. "Investors and investments of one Contracting Party in the territory of the other Contracting Party shall comply with all laws and regulations in force in that Party, which are consistent with its obligations in the present Treaty". ${ }^{48}$

Dalam pasal 8 ayat (1) dan (5) UU Nomor 25 tahun 2007 tentang Penanaman Modal ditegaskan bahwa terhadap penanam modal asing juga harus tunduk pada ketentuan hukum nasional, sebagai berikut :

\footnotetext{
${ }^{46}$ BIT antara Perancis dan Dominika

${ }^{47}$ Dafina Atanasova, Op.Cit.[57].

48 ibid. [58].
} 
(1) Penanam modal dapat mengalihkan aset yang dimilikinya kepada pihak yang diinginkan oleh penanam modal sesuai dengan ketentuan peraturan perundangundangan.

(5) Ketentuan sebagaimana dimaksud pada ayat (1) tidak mengurangi:

a. kewenangan Pemerintah untuk memberlakukan ketentuan peraturan perundang-undangan yang mewajibkan pelaporan pelaksanaan transfer dana;

b. hak Pemerintah untuk mendapatkan pajak dan/atau royalti dan/atau pendapatan Pemerintah lainnya dari penanaman modal sesuai dengan ketentuan peraturan perundang-undangan;

c. pelaksanaan hukum yang melindungi hak kreditor; dan

d. pelaksanaan hukum untuk menghindari kerugian negara

\section{c. Klausula Applicable Law (hukum yang berlaku)}

Untuk lebih mudah dalam menegaskan counter-claim, mengingat pengadilan arbitrase mempertimbangkan klausula yang sesuai dengan yurisdiksinya, maka ketentuan hukum yang berlaku dalam pe rjanjian harus memuat hukum domestik negara tersebut untuk memasukkan tindakan apa saja yang dapat digugat dalam counter-claim baik dalam kontrak ataupun kewajiban investor yang bedasarkan peraturan domestik host state. "The arbitral tribunal established under this Article shall reach its decision on the basis of national laws and regulations of the Contracting Party, which is a party to the dispute, the provisions of the present Agreement, as well as applicable rules of international law". ${ }^{49}$

\section{Kesimpulan}

Counter-claim dalam ISDS diperlukan karena counter-claim dalam perjanjian arbitrase adalah hal baru sehingga belum ada aturan yang seragam, counter-claim juga dapat meningkatkan efisiensi peradilan dan menjamin hasil yang konsisten karena berada di forum yang sama serta bagi host state, counter-claim berfungsi sebagai alat guna menghapus reputasi host state yang rusak karena tuduhan tidak berdasar yang diajukan oleh investor. Namun terdapat tantangan bagi host state untuk dapat menyatakan counter-claim yakni : counter-claim harus berada di bawah

\footnotetext{
${ }^{49}$ ibid. [59].
} 
persetujuan pihak yang bersengketa (host state dan investor), dan counter-claim harus memiliki hubungan yang erat dengan klaim utama.

Saat ini BIT Indonesia masih belum mengakomodasi klausula counterclaim. Ada beberapa opsi dalam mengadopsi klausula counter-claim, yakni: Melalui klausula yurisdiksi yaitu bisa dengan memperluas klausula yurisdiksi atau memasukkan klausula counter-claim secara tegas. Menambah kewajiban investor untuk patuh terhadap hukum negara penerima investasi, melalui klausula applicable law atau hukum yang berlaku.

\section{Daftar Bacaan}

\section{Buku}

Adolf Huala, Hukum Penyelesaian Sengketa Internasional (PT. Raja Grafindo Persada 2004).

-----------Hukum Ekonomi Internasional Suatu Pengantar (CV. Keni Media 2010).

Hertanti, Rachmi dan Rika Febriani, Bilateral Investment Treaty (BITs) "Negara VS Korporasi” Seri Buku Panduan Memahami: Perjanjian Investasi Internasional dan Gugatan Terhadap Indonesia (Indonesia for Global Justice 2014).

Kusumaatmadja, Mochtar, dan Etty R Agoes, Pengantar Hukum Internasional (Alumni 2010).

United Nations, Yearbook of the International Law Comission 1978 Volume II Part Two (United Nations 1979).

United Nations Conference on Trade and Development, UNCTAD Series on Issues in International Investment Agreement II: National Treatment, (United Nations 1999).

Bilateral Investment Treaties 1999-2006: Trends in Investment Rulemaking (United Nations 2007).

-UNCTAD Series on Issues in International Investment Agreement II: Fair and Equitable Treatment (United Nations 2012).

-UNCTAD Series on Issues in International Investment Agreement II: Expropriation (United Nations 2012). 
-ISDS Unctad Series on Issues in International Investment Agreements II, (United Nation 2014).

\section{Jurnal}

S. D. Franck, 'Foreign Direct Investment: Investment Treaty Arbitration and the Rule of Law', (2007), Global Business \& Development Law Journal.

Marc Jacob, 'Investment Bilateral Treaties' (2013) Max Planck Encyclopedia of Public International Law (MPEPIL).

UNCTAD, 'Investor-State Dispute Settlement: Review Of Developments In 2017', (2018). [1].

Atanasova, Benoit and Ostřanský, 'The Legal Framework for Counterclaims in Investment Treaty Arbitration', (2014), Journal of International Arbitration.

E Aisbett, 'Bilateral Investment Treaties And Foreign Direct Investment: Correlation Versus Causation', (2007), 1032 Cudare Working Paper.

Wolfgang Alschner, 'Americanization of the BIT Universe: The Influence of Friendship, Commerce and Navigation (FCN) Treaties on Modern Investment Treaty Law', (2002), 5 Goettingen Journal of International Law.

\section{Perundang-undangan}

Undang-Undang Nomor 25 Tahun 2007 tentang Penanaman Modal. Lembaran Negara RI Tahun 2007, No 67. Tambahan Lembaran Negara RI, No.4724. Sekretariat Negara. Jakarta. 2007.

Undang-Undang Nomor 1 Tahun 1967 tentang Penanaman Modal Asing. Lembaran Negara RI Tahun 1967, No.1. Tambahan Lembaran Negara RI, No. 2818. Sekretariat Negara. Jakarta. 1967.

Undang-Undang No. 5 tahun 1968 tentang Persetujuan atas Konvensi tentang Penyelesaian Perselisihan antara Negara dengan Warga Negara Asing mengenai Penanaman Modal. Lembaran Negara No. 32 Tahun 1968. Sekretariat Negara. Jakarta. 1968.

Undang-Undang Tentang Nasionalisasi Perusahaan-Perusahaan Milik Belanda, Undang-Undang Nomor 86 Tahun 1958, Lembaran Negara Nomor 162 Tahun 1958

Draft Template Indonesia mengenai Perjanjian Peningkatan dan Perlindungan Penanaman Modal. 2015. 
Vienna Convention on the Law Treaties 1969 (signed at Vienna 23 May 1969, entered into force on 27 January 1980).

Treaty Between The Government Of The United States Of America And The Government Of The Republic Of Azerbaijan Concerning The Encouragement And Reciprocal Protection Of Investment (Signed August 1, 1997, entered Into Force August 2, 2001)

\section{Laman}

The Directorate General for Trade of the Europian Commission, 'Factsheet on Investor-State Dispute Settlement : Europian Union'. (Europian Comission. 2015) <http://trade.ec.europa.eu/doclib/docs/2015/january/tradoc_153046. pdf $>$ accessed 04 Maret 2019.

UNCTAD, 'Review of ISDS Decissions in 2018', (2018) <https:// investmentpolicyhub.unctad.org/News/Database/Home/1604> accessed 4 Maret 2019.

HOW TO CITE: Nabilla Zelda Nasution, 'Klausula Counter-claim dalam Bilateral Investment Treaty Indonesia' (2019) Vol. 2 No. 6 Jurist-Diction. 
--halaman ini sengaja dibiarkan kosong-- 